\title{
Uso racional de antimicrobianos
}

\section{Rational use of antimicrobials}

\author{
Letícia M. Mota ${ }^{1}$, Fernando C. Vilar ${ }^{2,4}$, Larissa B. A. Dias ${ }^{3}$, Tiago F. Nunes ${ }^{3,4}$, Julio C. Moriguti ${ }^{5}$
}

\begin{abstract}
RESUMO
A administração inadequada de antimicrobianos é capaz de comprometer a resposta clínica do paciente, aumentar custos com internação e contribuir para o surgimento de bactérias multirresistentes. Nesse contexto, o uso racional de antimicrobianos é benéfico para o paciente infectado e também para a instituição de saúde. A indicação desta classe de drogas deve levar em conta o hospedeiro, o agente infeccioso e o antimicrobiano propriamente dito. Assim, sua utilização deve ser baseada no conhecimento dos conceitos de colonização, contaminação e infecção, noções de microbiologia clínica, coleta de culturas, microbiota habitual do corpo humano, e mecanismos, espectro de ação, farmacocinética, farmacodinâmica e efeitos colaterais dos antimicrobianos. A revisão desses tópicos procura fornecer subsídios para escolha do antimicrobiano mais adequado para o tipo de infecção, tempo de tratamento previsto, critérios de falha e resposta clínica à droga prescrita, além de nortear possível troca de terapia ao longo do tratamento.
\end{abstract}

Palavras-chave: Agentes Antibacterianos. Antibióticos. Uso de Medicamentos.

\section{Introdução}

Os antimicrobianos são substâncias naturais (antibióticos) ou sintéticas (quimioterápicos) que agem sobre microorganismos inibindo o seu crescimento ou causando a sua destruição. É a segunda classe de droga mais utilizada sendo responsável por 20 a $50 \%$ das despesas hospitalares. ${ }^{1}$ É prescrita em larga escala em atendimentos ambulatoriais e também como automedicação. ${ }^{2}$ Esta ampla utilização de antimicrobianos pode afetar de forma significativa não somente a microbiota do paciente que o utiliza, mas também a ecologia microbiana dos outros pacientes. ${ }^{3}$
O organismo humano é colonizado por uma microbiota diversificada em locais como trato gastrointestinal, pele e genitália. Esses sítios colonizados sofrem pressão seletiva gerada pelo uso dos antimicrobianos que acabam por eliminar parte das bactérias existentes e permitir que as demais sobrevivam e promovam um desequilíbrio. Outro risco enfrentado pelo uso abusivo de antimicrobianos é o surgimento de surtos intra-hospitalares envolvendo bactérias multirresistentes. ${ }^{4}$ Esses eventos de desequilíbrio da microbiota humana e surgimento de bactérias resistentes aumentam a morbidade dos pacientes, prolongam o tempo de internação e promovem custos adicionais aos servi-
1 Ex-Médica Assistente do Serviço de Controle de Infecção Hospitalar do Hospital Estadual de Ribeirão Preto.

2 Médico Assistente do Serviço de Controle de Infecção Hospitalar do Hospital Estadual de Ribeirão Preto.

3 Médico Assistente da Clínica Médica do Hospital Estadual de Ribeirão Preto.

4 Pós-graduando da Área de Clínica Médica da FMRP-USP.

5 Diretor de Atividades Clínicas do Hospital Estadual de Ribeirão Preto e Professor Livre-Docente da Divisão de Clínica Médica Geral e Geriatria da FMRP-USP.
Correspondência: Fernando Crivelenti Vilar Hospital Estadual de Ribeirão Preto Avenida Independência, 4750 14026-160- Ribeirão Preto - SP Telefone: $16-3602-7100$ 
ços de saúde, que podem ser evitados com o uso racional dos antimicrobianos.

O uso inadequado de antimicrobianos é descrito há vários anos. Scheckler e Bennet ${ }^{5}$, em 1970, observaram que $62 \%$ das indicações de antimicrobianos eram feitas a pacientes sem infecção. Kunin ${ }^{6}$ concluiu em artigo publicado em 1973 que 50\% das prescrições de antimicrobianos não tinham indicação. Jogerst e Dippe ${ }^{7}$, em 1981, classificaram como inadequadas $59 \%$ das prescrições antimicrobianas.

\section{Uso inadequado de antimicrobianos}

Existem alguns fatores que contribuem direta ou indiretamente para o uso inadequado de antimicrobianos tanto na condução dos pacientes ambulatoriais, como em pacientes internados. São eles:

1. A ampla distribuição de amostras de antimicrobianos e disponibilidade de compra em farmácias, facilitando o acesso ao consumo pela população, levando a utilização indiscriminada e a automedicação; ${ }^{8}$

2. Dúvida diagnóstica entre infecções bacterianas e infecções virais: muitas vezes manifestações febris agudas virais de evolução clínica autolimitada como infecções por rotavírus e vírus influenza são confundidas com infecções bacterianas e motivam o uso de antimicrobianos, inclusive como sintomáti$\cos ;^{9}$

3. Ausência de Programa de Uso Racional de Antimicrobianos: a falta de comissão de uso racional de antimicrobianos no âmbito hospitalar com implantação de protocolos, auditoria e consultoria possibilitam o uso indiscriminado destas drogas em pacientes internados e aumenta o risco de surgimento de bactérias resistentes; ${ }^{10}$

4. Idéia errônea de que a eficácia no tratamento das infecções é maior com o uso de antimicrobiano de amplo espectro, podendo levar a situações como:

a) Destruição da microbiota intestinal provocando diarréia e intolerância ao medicamento;

b) Estimular o desencadeamento de mecanismos de resistência com o surgimento de bactérias multirresistentes ao longo do tempo e infecções por mais de um agente;

c) Resultar em insucesso no tratamento e gerar aumento de custos para a instituição.

5. Desconhecimento da prescrição de antimicrobianos quanto a doses, intervalos e diluições, contribuindo para o insucesso no tratamento e surgimento de reações adversas nos pacientes.

\section{Bases para prescrição de antimicro- biano}

A prescrição adequada de antimicrobiano envolve:

1. Conhecimento a respeito do hospedeiro;

2. Diferença entre colonização, contaminação e infecção;

3. Coleta de culturas;

4. Microbiologia clínica;

5. Microbiota habitual humana;

6. Antibióticos: mecanismo e espectro de ação, farmacocinética, farmacodinâmica e efeitos colaterias.

\section{Hospedeiro}

Para a prescrição de antimicrobianos é fundamental conhecer alguns dados a respeito do paciente ${ }^{10}$ : idade, história pregressa de hipersensibilidade a antimicrobianos, funções hepática e renal, possível gravidez, estado imunológico, coagulopatias, história de alergias, uso recente de antibióticos, se está hospitalizado há muito tempo ou se foi hospitalizado recentemente, doença de base, possível insuficiência de órgãos e o possível sítio de infecção. Somente após a análise destas variáveis relacionadas ao paciente é que deve ser feita a escolha do antimicrobiano.

\section{Diferença entre colonização, contaminação e infecção}

Muitos pacientes apresentam positividade em exames de cultura para bactérias na urina, sangue, secreções e outros, e não possuem necessariamente quadros clínicos de infecção. Para tanto, é preciso conceituar outras situações nas quais há positividade na cultura e não existe infecção. Alguns pacientes podem se manter, por exemplo, colonizados por bactérias na urina sem que haja repercussão clínica. Há também o risco de contaminação de materiais, o que justifica determinadas situações de culturas positivas em pacientes sem infecção. Os conceitos aplicáveis são ${ }^{11}$ :

2.1 Colonização: presença de microorganismos com multiplicação no hospedeiro sem manifestações clínicas ou resposta imunológica.

2.2 Contaminação: presença de microorganismo em cultura sem que signifique colonização ou infecção, ou presença de microorganismos em objetos inanimados.

2.3 Infecção: fenômeno causado pela replicação de microorganismo no hospedeiro levando a resposta imunológica. 


\section{Coleta de cultura}

Devem-se coletar os materiais biológicos para cultura bacteriana (sangue, urina, fezes, secreções, escarro, líquido ascítico/pleural, líquor, etc) de acordo com o diagnóstico clínico de infecção e provável foco detectado. A tentativa de isolar os agentes envolvidos no processo infeccioso e verificar sua sensibilidade aos antimicrobianos, principalmente nos casos sem definição diagnóstica, é de grande importância na escolha desta droga. Uma cultura positiva de paciente infectado pode motivar troca antimicrobiana com direcionamento de espectro, melhora no tratamento e redução de custos. Alguns materiais têm maiores riscos de contaminação de coleta (urina) e outros não são estéreis habitualmente (fezes, escarro e secreções), despertando cautela em sua interpretação. Entretanto, materiais como sangue, osso, líquido ascítico, pleural e líquor são considerados estéreis e, portanto, mais confiáveis para auxílio no diagnóstico quando isolado o agente.

\section{Microbiologia clínica}

A classificação das bactérias baseia-se em suas características morfológicas e bioquímicas. O conhecimento a respeito de testes de identificação bacteriana e processamento de amostras de cultura coletados pode auxiliar no tratamento antimicrobiano. Situações como identificação bacteriana pela coloração de Gram é um recurso rápido e útil que pode nortear a escolha de antimicrobiano empírico mais direcionado para grupo específico de agentes.

Morfologicamente as bactérias são analisadas pela sua aparência macroscópica (Colônia em estria, picada, modo de crescimento) ou estrutura microscópica (tamanho; forma - bacilos, cocos; arranjo das células, flagelos, cápsulas, esporos). ${ }^{12}$

A diferenciação bioquímica é feita laboratorialmente por meio de culturas, coloração de Gram e coloração para álcool-ácido resistência. Há vários meios de cultura que tentam proporcionar condições ideais para o crescimento e identificação das bactérias em laboratório. A coloração de Gram revela diferenças entre as bactérias de paredes celulares espessas de peptideoglicanas (Gram-positivas-violáceas) e as com membranas externas de polissacarídeos lábeis ao álcool ou acetona (Gram-negativas-róseas). Outros testes também são utilizados para facilitar a classificação e divisão das bactérias cultivadas, de modo a encaixálas adequadamente num subgrupo mais específico. ${ }^{12}$
Nas Tabelas 1 e 2 encontra-se a classificação das bactérias pela coloração de Gram, que pode ser fundamental na escolha inicial do antimicrobiano (atividade para bactérias Gram-positivas ou negativas).

\section{Microbiota normal}

A pele e as mucosas abrigam uma variedade de microorganismos que se distribuem em dois grupos: a microbiota transitória e a microbiota residente. A microbiota transitória consiste de organismos não-patogênicos ou potencialmente patogênicos, que habitam a pele ou as mucosas durante horas, dias ou semanas. É originária do meio ambiente, geralmente não produz doença e não se estabelece de modo permanente na superfície do corpo. O termo microbiota residente normal é usado para descrever várias bactérias e fungos que são residentes permanentes de certos sítios como pele, nasofaringe, laringe, traquéia, esôfago, estômago, cólon e trato geniturinário. A microbiota residente quando alterada, tende a prontamente se recompor.

Os membros da flora transitória são geralmente de pouca importância, desde que a microbiota normal permaneça íntegra. Entretanto, se a microbiota residente for alterada, microrganismos transitórios podem proliferar e produzir doença.

Desde o nascimento, as pessoas vivem expostas a biosfera composta de inúmeros microrganismos. A composição desse ambiente é dinâmica, portanto a microbiota normal varia tanto em número como em tipo, de um local para outro. Regiões como o sistema nervoso central, o sangue, os brônquios inferiores e os alvéolos, o fígado e o baço, os rins e a bexiga são, em geral, totalmente livres de microorganismos.

Os microorganismos da microbiota normal têm papel importante tanto na manutenção da saúde, quanto na possibilidade de causar doença. Eles podem constituir um mecanismo de defesa do hospedeiro dificultando a multiplicação de outros patógenos em seus nichos ecológicos. Se a microbiota normal é suprimida, os patógenos podem crescer e causar doença. Em indivíduos imunodeprimidos, os próprios microorganismos residentes podem causar doença. Alguns destes organismos não são patogênicos quando localizados na região anatômica usual, mas podem ser patogênicos em outros locais do corpo. $\mathrm{O}$ uso indiscriminado de antimicrobiano pode selecionar e permitir aumento em populações de microorganismos residentes, tornando-os patogênicos.

É importante conhecer a microbiota normal do corpo humano para identificar as alterações que pos- 


\section{Tabela 1}

Classificação das bactérias pelo coloração de Gram (em negrito estão as mais encontradas)

\begin{tabular}{|c|c|c|c|c|c|}
\hline \multicolumn{6}{|c|}{ Bactérias Aeróbias } \\
\hline \multicolumn{2}{|c|}{ Gram Positivos } & \multicolumn{4}{|c|}{ Gram Negativos } \\
\hline Cocos & Bacilos & Cocos & Bacilos & & Coco-bacilos \\
\hline Aerococcus & Actinomyces spp & $\begin{array}{l}\text { Moraxella } \\
\text { catarrhalis }\end{array}$ & Enterobactérias & Fermentadores & $\begin{array}{l}\text { Actinobacillus } \\
\text { spp }\end{array}$ \\
\hline Alloiococcus & Arcanobacterium & Neisseria spp. & Buvdica aquatica & Aeromonas spp & Afipia spp \\
\hline Dolosigranulum & Aureobacterium & & Cedecea spp & Chromobacterium & Arcobacter spp \\
\hline Enterococcus spp & Bacillus spp & & Citrobacter spp & Plesiomonas & Bartonella spp \\
\hline Gemella & Corynebacterium & & Edwardsiella spp & Pasteurella spp & Brucella app \\
\hline Globicatella & Dermabacter & & Enterobacter spp & Vibrio spp & Bordetella spp \\
\hline Helcococcus & Erysipelothrix & & Escherichia coli & $\begin{array}{l}\text { NÃO } \\
\text { fermentadores }\end{array}$ & $\begin{array}{l}\text { Calymmato } \\
\text { bacterium }\end{array}$ \\
\hline Lactococcus & Gardnerella & & Escherichia spp & $\begin{array}{l}\text { Acinetobacter } \\
\text { spp }\end{array}$ & $\begin{array}{l}\text { Campylobacter } \\
\text { spp }\end{array}$ \\
\hline Leuconostoc & Gordona & & Ewingella & Agrobacterium & $\begin{array}{l}\text { Capnocyto- } \\
\text { phaga spp }\end{array}$ \\
\hline Micrococcus spp & Kurthia & & Hafnia alvei & Alcaligenes sp & $\begin{array}{l}\text { Cardio- } \\
\text { bacterium }\end{array}$ \\
\hline Pediococcus & Lactobacillus & & Klebsiella spp & Bergeyella & Chlamydia spp \\
\hline $\begin{array}{l}\text { Staphylococcus } \\
\text { spp }\end{array}$ & Listeria spp & & Kluyvera spp & $\begin{array}{l}\text { Brevundimonas } \\
\text { spp }\end{array}$ & Coxiella bunetii \\
\hline Stomatococcus & Microbacterium & & Leclercia & Burkholderia spp & $\begin{array}{l}\text { Eikenella } \\
\text { corrodens }\end{array}$ \\
\hline Streptococcus spp & Mycobacterium spp & & Leminorella spp & $\begin{array}{l}\text { Chryseobacterium } \\
\text { spp }\end{array}$ & Ehrlichia spp \\
\hline Tetragenococcus & Nocardia spp & & Moellerella & $\begin{array}{l}\text { Chryseomonas } \\
\text { luteola }\end{array}$ & $\begin{array}{l}\text { Francisella } \\
\text { spp }\end{array}$ \\
\hline \multirow[t]{14}{*}{ Vagococcus } & Oerskovia & & Morganella spp & Comamonas spp & $\begin{array}{l}\text { Haemophilus } \\
\text { spp }\end{array}$ \\
\hline & Rhodococcus & & Pantoea & $\begin{array}{l}\text { Empedobacter } \\
\text { brevis }\end{array}$ & Helicobacter spp \\
\hline & Rothia & & Proteus spp & Flavimonas & Kingella spp \\
\hline & Tsukamurella & & Providencia & $\begin{array}{l}\text { Flavobacterium } \\
\text { spp }\end{array}$ & Legionella spp \\
\hline & \multirow[t]{10}{*}{ Turicella } & & Rahnella aquatilis & Methylobacterium & Psychrobacter \\
\hline & & & Salmonella spp & Moraxella spp & Rickettsia spp \\
\hline & & & Serratia app & Ochrobactrum & Streptobacillus \\
\hline & & & Shigella spp & Oligella spp & Suttonella \\
\hline & & & Tatumella ptyseos & Pseudomonas spp & \\
\hline & & & Trabulsiella & Roseomonas spp & \\
\hline & & & Yersinia spp & Shewanella spp & \\
\hline & & & Yokenella & Sphingobacterium & spp \\
\hline & & & & Stenotrophomonas & \\
\hline & & & & Weeksella virosa & \\
\hline
\end{tabular}




\section{Tabela 2}

Classificação das bactérias pela coloração de Gram (em negrito estão as mais encontradas)

\begin{tabular}{ll}
\hline \multicolumn{2}{c}{ Bactérias Anaeróbias } \\
Gram Positivos & Gram Negativos \\
\hline Cocos & Cocos \\
Gemella & Acidaminococcus \\
Peptococcus & Megasphaera \\
Peptostreptococcus & Veillonella
\end{tabular}

Reuminococcus spp

Staphylococcus

Streptococcus spp

\begin{tabular}{|c|c|}
\hline Bacilos & Bacilos \\
\hline Actinomyces spp & Anaerobiospirillum \\
\hline Atopobium spp & Anaerorhabdis \\
\hline Bifidobacterium spp & Bacterioides spp \\
\hline Clostridium spp & Bilophila \\
\hline Eubacterium spp & Campylobacter spp \\
\hline Filifactor & Catonella \\
\hline Lactobacillus spp & Centipeda \\
\hline Mobiluncus spp & Desulfomonas \\
\hline \multirow[t]{12}{*}{ Propionibacterium spp } & Desulfovibrio \\
\hline & Dialister \\
\hline & Dichelobacter \\
\hline & Fusobacterium spp \\
\hline & Hallela \\
\hline & Johnsonella \\
\hline & Leptotrichia \\
\hline & Mitsuokella \\
\hline & Porphyromonas spp \\
\hline & Prevotella spp \\
\hline & Selenomonas spp \\
\hline & Tissierela \\
\hline
\end{tabular}

sam causar infecções, sem superestimar ou subestimar os microrganismos isolados. Assim, a prescrição de antimicrobiano será específica para cada microorganismo, promovendo tratamento mais próximo ao ideal e permitindo melhor evolução ao paciente.

\section{6) Antimicrobianos}

Os agentes antimicrobianos devem ser escolhidos após a avaliação dos pontos mencionados acima. Idealmente esta escolha deveria seguir o isolamento do microorganismo em cultura, porém, muitas vezes é feita de modo empírico, que deveria ser a exceção, e não a regra.

O uso empírico de antimicrobiano não prescinde, contudo, da coleta de amostras para cultura antes do início da antibioticoterapia. Deve ser baseado nos itens destacados anteriormente, na epidemiologia dos agentes e seus respectivos sítios de infecção. Caso houver mais de um agente antimicrobiano adequado para o tratamento da infecção, deve-se escolher aquele que possua menor toxicidade, via de administração mais adequada, menor indução de resistência bacteriana, penetração e concentração eficaz no sitio da infecção, posologia mais cômoda e menor custo. ${ }^{10}$ Para isso, o mecanismo e espectro de ação, farmacocinética, farmacodinâmica e efeitos colaterias dos antimicrobianos tem que ser conhecidos.

\section{Espectro de ação contra bactérias}

Dentre os vários grupos de antimicrobianos e seus respectivos espectros de ação contra as bactérias, ressalta-se um dos grupos maiores, os betalactâmicos. Os antibióticos beta-lactâmicos incluem o grupo das Penicilinas (naturais e semi-sintéticas), Cefalosporinas (primeira à quarta geração), Carbapenêmicos, Monobactâmicos e associações com inibidores da beta-lactamase. A principal característica de tal grupo é a presença do grupamento químico heterocíclico azetidinona denominado anel betalactâmico. ${ }^{13} \mathrm{O}$ mecanismo de ação resulta na inibição da síntese da parede celular bacteriana, através do bloqueio da transpeptidação do composto peptidoglicano, resultando em ação bactericida. Os betalactâmicos têm ação variada contra bactérias Gram negativas, Gram positivas, anaeróbias e aeróbias de acordo com os seus subgrupos. Alguns exemplos de beta-lactâmicos:

\section{- Penicilinas:}

Penicilina G (Benzil-penicilina): penicilina cristalina, procaína e benzatina

Penicilina $\mathrm{V}$

- Penicilinas semi-sintéticas:

Oxacilina e Meticilina

- Aminopenicilinas:

Ampicilina e Amoxicilina 


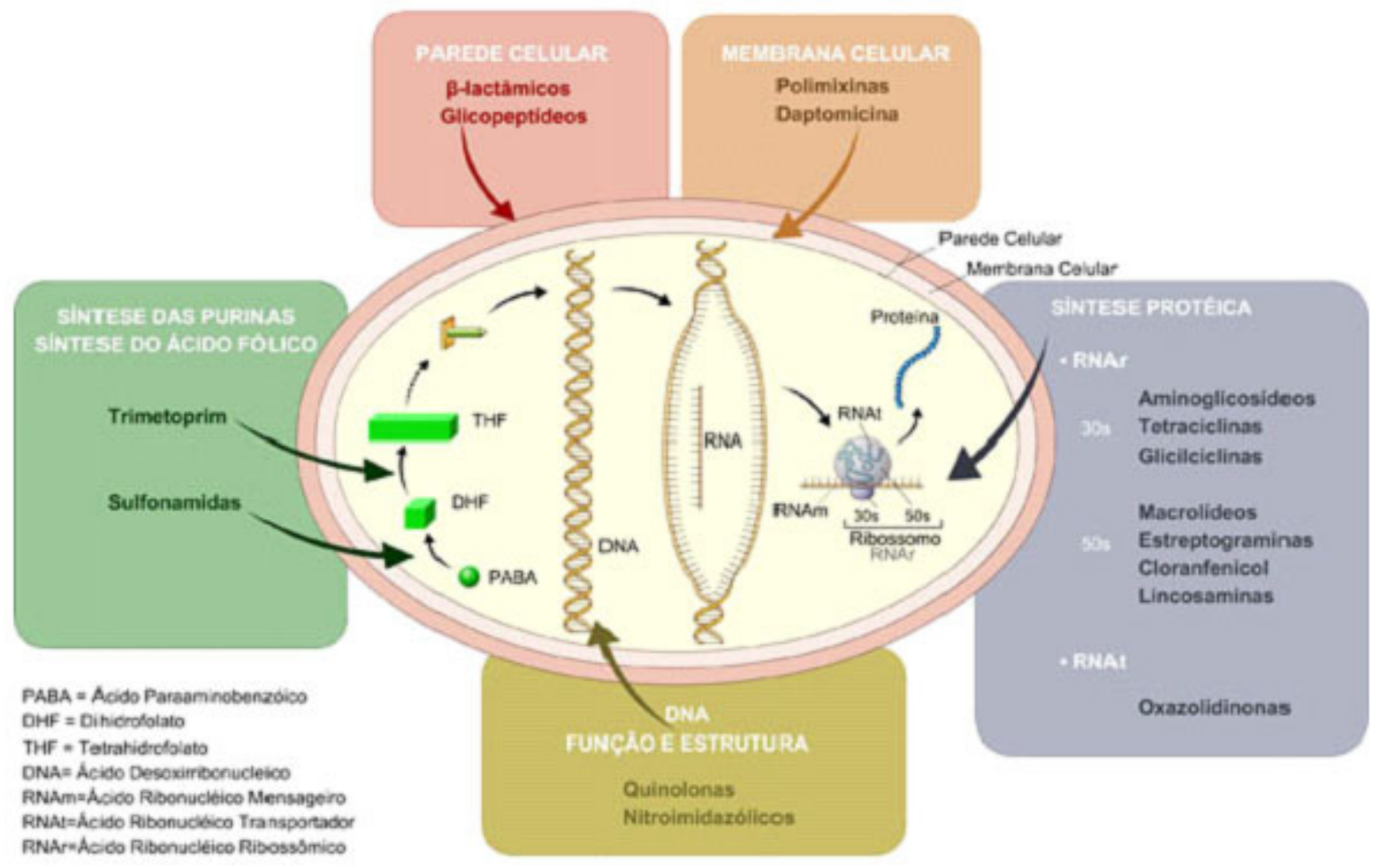

Figura 1: Mecanismo de ação dos antimicrobianos ${ }^{13}$

- Carboxipenicilinas:

Carbenicilina e Ticarcilina

- Ureidopenicilinas:

Piperacilina

- Carbapenêmicos:

Imipenem, Meropenem e Ertapenem

- Monobactâmicos:

Aztreonam

- Inibidores da beta-lactamase:

Ácido Clavulânico/amoxicilina, Tazobactam/ piperacilina, Sulbactam/ampicilina

- Cefalosporinas:

Primeira geração: Cefalexina, Cefadroxil, Cefalotina, Cefazolina

Segunda geração: Cefoxitina, Cefuroxime, Cefaclor Terceira geração: Ceftriaxone, Cefotaxime

Terceira geração anti-Pseudomonas: Ceftazidime

Quarta-geração: Cefepime

\section{Farmacocinética e Farmacodinâmica ${ }^{14}$}

Farmacocinética está relacionada à absorção, distribuição, metabolismo e excreção do antimicrobiano, enquanto a farmacodinâmica descreve a concentração sanguínea, concentração no sítio da infecção e os efeitos tóxicos da droga durante seu uso. Conhecimentos sobre as características farmacodinâmicas e farmacocinéticas do antimicrobiano (inibição de crescimento, ação bactericida e efeito pós-antibiótico) fornecem a base racional para determinar a dose ideal e o intervalo entre elas num tratamento com estes agentes.

A figura 2 representa os conceitos de farmacocinética e farmacodinâmica do antimicrobiano na cura do processo infeccioso.

Os antimicrobianos podem ser classificados em dois grupos de acordo com a sua atividade: bactericidas ou bacteriostáticos. Os primeiros agem matando o microorganismo e são representados pelos betalactâmicos, vancomicina, aminoglicosídeos, fluoroquinolonas, daptomicina e metronidazol. Drogas bacteriostáticas são os macrolídeos, clindamicina, tetraciclinas, sulfonamidas, linezolida e cloranfenicol. Os bacteriostáticos são suficientes para a maioria das infecções, porém em pacientes com sistema imune comprometido (como agranulocitose) e sítios de infecção nos quais o crescimento do agente tem que ser interrompido (meningite e endocardite infecciosa) é necessário o uso de bactericida. 


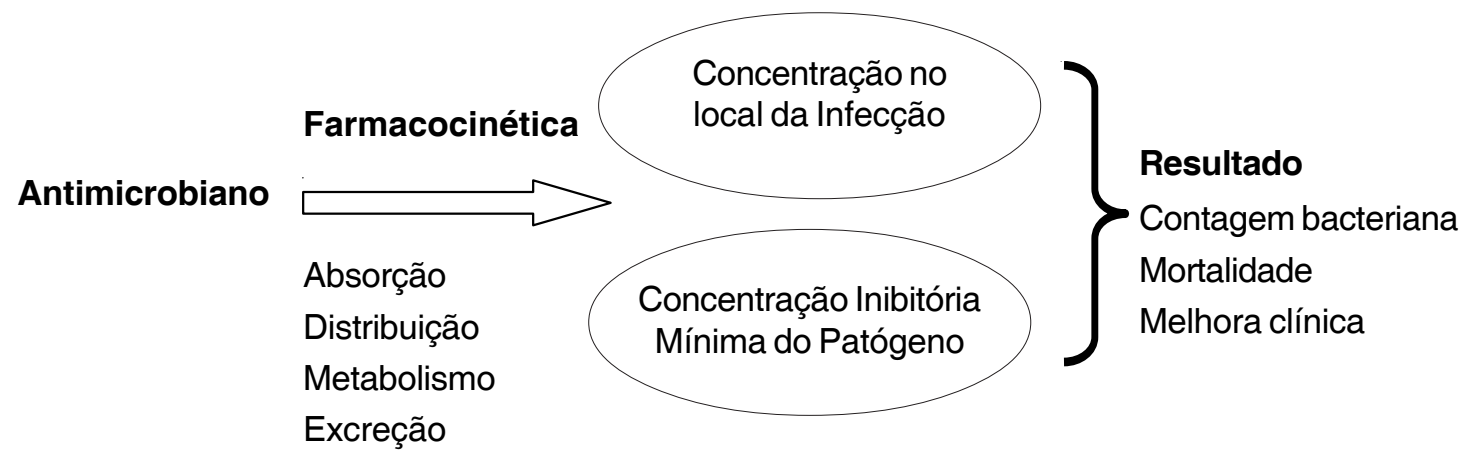

Farmacodinâmica

Eliminação tempo-dependente

Eliminação concentração-dependente

Efeito pós-antibiótico

Figura 2: Farmacocinética e Farmacodinâmica dos antimicrobianos.

Outro conceito importante na farmacodinâmica dos antimicrobianos é a concentração inibitória mínima (termo consagrado na língua inglesa como MIC - minimal inhibitory concentration). O MIC é definido como a mínima concentração de antimicrobiano suficiente para impedir o crescimento bacteriano em uma suspensão contendo $10^{5}$ unidades formadoras de colônias após a incubação por uma noite e determina a sensibilidade in vitro do microorganismo aos agentes antimicrobianos.

\section{Efeitos colaterais ${ }^{15}$ :}

Efeitos colaterais dos antimicrobianos são reações adversas a estas drogas envolvendo um ou mais órgãos ou sistemas. Embora a maioria dos antibióticos seja segura considerando seu pequeno volume para uso, alguns antimicrobianos têm potenciais efeitos colaterais. A maioria dos eventos adversos relatados é específica de um agente e não da classe de antimicrobianos. A seguir, alguns efeitos colaterais reportados a classe de antimicrobianos: os beta-lactâmicos podem estar relacionados à febre originada por drogas e reações de farmacodermia; os aminoglicosídeos, mais comumente são nefrotóxicos e ototóxicos; a vancomicina pode provocar a chamada "Síndrome do Homem Vermelho" que consiste em rash cutâneo de face e região cervical durante a infusão rápida da droga; macrolídeos geralmente são causa de náuseas, vômitos, dor abdominal e diarréia quando utilizados por via oral, e podem provocar flebite quando utilizados na apresentação endovenosa, como a claritromicina; as quinolonas podem prolongar o intervalo QT e de- sencadear estado confusional agudo em idosos. Efeitos colaterais de drogas específicas têm que ser lembrados frente a qualquer alteração clínica/laboratorial em pacientes utilizando antimicrobianos.

\section{Tratamento antimicroblano}

\section{Introdução do antimicrobiano}

A decisão de iniciar tratamento antimicrobiano deve ser tomada quando há evidências de infecção por meio de dados clínicos (picos febris, presença de secreção purulenta), laboratoriais (hemograma com leucocitose e desvio à esquerda) e/ou de imagem, levando em conta os tópicos previamente abordados. A suspeita clinica pode ou não ser confirmada com cultura positiva para microrganismos, preferivelmente isolados de materiais considerados estéreis. Definido sinais e sintomas sugestivos de infecção, é necessária a procura de foco provável. A comprovação do sítio de infecção auxiliará na escolha do antimicrobiano empírico baseado na colonização habitual, patógenos mais comuns e penetração do antibiótico no sítio afetado.

A escolha do antimicrobiano empírico deve levar em conta a repercussão clínica da infecção bem como comorbidades que possam levar a piora clínica rapidamente. Pacientes imunossuprimidos ou criticamente enfermos demandarão início empírico precoce de antimicrobiano. Entretanto, pacientes sem comorbidades ou considerados estáveis clinicamente, comprometidos a exemplo por osteomielites, permitirão 
possível confirmação da bactéria envolvida na infecção por meio de culturas antes da introdução do antibiótico.

\section{Tempo de tratamento}

O tempo de tratamento antimicrobiano é variável de acordo com a resposta clínica inicial e foco infeccioso. Geralmente a duração deve variar de 7 a 14 dias. Pacientes com pneumonia que respondem bem com melhora clínica e redução de picos febris nas primeiras 48 horas podem ser tratados de 8 a 10 dias. Entretanto, situações como osteomielites agudas e endocardites demandam tempo de tratamento de quatro a seis semanas. Infecções com presença de abscesso, o tratamento antimicrobiano é indeterminado enquanto houver coleção. O tempo de tratamento ideal é aquele menor possível sem comprometimento da eficácia.

\section{Falhas no tratamento}

A persistência de febre e quadro clínico infeccioso denota falha ao antimicrobiano prescrito e pode ocorrer devido a:

1. Posologia inadequada do antimicrobiano: tratamentos com baixas doses e intervalos irregulares de antibiótico podem levar a não resposta ao tratamento e induzir maior risco de resistência pela pressão seletiva a outras bactérias não envolvidas na infecção;

2. Antimicrobiano empírico sem ação contra a bactéria causadora da infecção: a razão mais comum para esse tipo de falha é a negligência ao resultado das culturas e antibiograma e desconhecimento da epidemiologia dos agentes mais comuns para determinado foco infeccioso;

3. Presença de abscessos e tecidos necróticos: nestas situações é necessário, além do tratamento medicamentoso, desbridamentos de tecidos necróticos e drenagem de abscessos para resolução da infecção.

4. Antimicrobiano prescrito para situações nas quais não há infecção: outras doenças como neoplasias, doenças reumáticas, doenças hematológicas e farmacodermia, fazem diagnóstico diferencial com quadros infecciosos, podendo cursar com febre, alterações laboratoriais e clínicas semelhantes, nas quais o uso de antimicrobianos não terá sucesso.

\section{Alteração no tratamento antimicrobiano}

A troca de antimicrobiano no decorrer do tratamento pode acontecer motivada por: direcionamento de antimicrobiano de acordo com bactéria isolada em cultura, principalmente de material estéril; redução de custo sem perda de eficácia; adequação de posologia, transição de antimicrobiano administrado por via intravenosa para via oral, intervalos mais confortáveis ao paciente; piora clínica e necessidade de ampliar espectro. A suspensão do tratamento antimicrobiano iniciado pode ocorrer quando descoberto que as alterações apresentadas pelo paciente não tem causa infecciosa.

\section{Considerações Finais}

Considerando a escolha do antimicrobiano fundamentada na individualidade do paciente, nas noções de infecção, grupos bacterianos, microbiota habitual humana e características dos antibióticos, o antimicrobiano ideal deve: ter ação bactericida; espectro de ação mais específico possível; menor concentração inibitória mínima; maior biodisponibilidade em determinado sítio de infecção; melhor comodidade posológica; ser compatível com o estado clínico do paciente; menos tóxico e de menor custo.

\begin{abstract}
The inadequate administration of antimicrobials may compromise the clinical response of the patient, increase the costs during hospitalization and contribute to the appearance of multiresistant bacteria. In this context, the use of rational antimicrobials is beneficial to the infected patient and also to the health institution. The prescription of this drug type must take in account the host, the infectious agent and the antimicrobial itself. Thus, its utilization must be based on the knowledge of the concepts of colonization, contamination and infection, notions of clinical microbiology, culture collection, and habitual microbiota of the human body, and mechanisms, action specter, pharmacokinetics, pharmacodynamics and side effects of the antimicrobials. The revision of these topics pursuits to provide subsidies to the choice of the most adequate antimicrobial to the type of infection, foreseen treatment time, failure criteria and clinical answer to the prescribed drug, besides guide possible change of therapy along the treatment.
\end{abstract}

Key words: Anti-Bacterial Agents. Antibiotics. Drug Utilization. 


\section{Referências Bibliográficas}

1. Sáez-Llorens $X$, Castrejón-De Wong M, Castaño E, De Suman O, Morós D, De Atencio I. Impact of an antibiotic restriction policy on hospital expenditures and bacterial susceptibilities: a lesson from a pediatric institution in a developing country. Pediatr Infect Dis J 2000; 19: 200-6.

2. McCaig LF, Hughes JM. Trends in antimicrobial drug prescribing among office-based physicians in the United States. JAMA 1995;273:214-9.

3. Archibald L, Phillips L, Monnet D, McGowan Jr JE, Tenover F, Gaynes R. Antimicrobial resistance in isolates from inpatients and outpatients in the United States: increasing importance of the intensive care units. Clin Infect Dis. 1997;24: 211-5.

4. Shlaes DM, Gerding DN, John Jr JF, Craig WA, Bornstein DL, Duncan RA, et al. SHEA Position Paper. Society for Healthcare Epidemiology of America and Infectious Diseases Society of America Joint Committee on the Prevention of Antimicrobial Resistance: Guidelines for the Prevention of Antimicrobial Resistance in Hospitals. Infect Control Hosp Epidemiol. 1997;18:275-91.

5. Sheckler WE, Bennett JV. Antibiotic usage in seven community hospitals. JAMA. 1970; 213:264-7.

6. Kunin CM, Tupasi T, Craig WA. Use of antibiotics: a brief exposition of the problem and some tentative solutions. Ann Intern Med 1973;79:555-60.

7. Jogerst GJ, Dippe SE. Antibiotic use among medical specialties in a community hospital. JAMA 1981;245:842-6.
8. Holloway K. WHO activities to contain antimicrobial resistance and promote Drug and Therapeutic Committees. Geneva: World Health Organization, Departament of Essential Drugs and Medicines Policy, 2003. (Palestra)

9. Niederman MS. Principles of appropriate antibiotic use. Int J Antimicrob Agents. 2005; 26 (Suppl 3): S170-5.

10. Brasil. Ministério da Saúde. Agência Nacional de Vigilância Sanitária. Unidade de Controle de Infecção em Serviços de Saúde. Consenso sobre o uso racional de antimicrobianos. Brasília. 2001.

11. Levin ASS, Dias MBGS. Antimicrobianos: um guia de consulta rápida. São Paulo: Atheneu, 2006. p. 17-24

12. Murray PR, Baron EJ, Pfaller MA, Tenover FC, Yolken RH. Manual of clinical microbiology. 8th ed. American Society for Microbiology Press. Washington, DC. 2003.

13. Medeiros EAS, Stempliuk VA, Santi LQ, Sallas J. Curso medidas de prevenção de resistência microbiana e programa de uso racional de antimicrobianos em serviços de saúde. OPAS, ANVISA, Coordenação Geral de Laboratórios de Saúde Pública - CGLAB/SVS/MS e Disciplina de Infectologia da Universidade Federal de São Paulo, 2007.

14. Levison ME. Pharmacodynamics of antimicrobial drugs. Infect Dis Clin North Am. 2004;18: 451-65.

15. Cunha BA. Antibiotics side effects. Med Clin North America. 2001;85:149-86. 